\title{
Degradação socioambiental urbana, políticas públicas e cidadania
}

\section{Urban socioenvironmental degradation, public policies an citizenship}

\author{
Myrian Del Vecchio de LIMA* \\ Cynthia RONCAGLIO**
}

\begin{abstract}
RESUMO
Resultado de reflexões desenvolvidas no exercício de diferentes disciplinas, este artigo aponta alguns aspectos que norteiam a atual discussão sobre a degradação socioambiental urbana. Trata-se aqui, especialmente, de discutir a noção de degradação, a evolução da questão ambiental e o conseqüente desenvolvimento de políticas públicas voltadas para a solução dos problemas socioambientais urbanos e vinculadas ao exercício da cidadania, bem como à necessidade de se buscar uma visão complexa da realidade urbana, a partir de um (re)conhecimento da interação entre sociedade e natureza.
\end{abstract}

Palavras-chave: degradação socioambiental, ambiente urbano, políticas públicas e cidadania

\begin{abstract}
As a result from an interdisciplinary reflection, the present article deals with some aspects which direct the issue of urban socioenvironment degradation. The article focus on the notion of degradation, the evolution of the environment issue and the development of public policies which aim at the solution of urban socioenvironment problems, linked to citizenship activities, as well as at searching a complex view of the urban reality, through the (re)cognition of the interactionof society and nature.
\end{abstract}

Key-words: socioenvironment degradation, urban environment, public policies, citizenship

\footnotetext{
* Professora do Curso de Jornalismo da UFPR, Doutoranda em Meio Ambiente e Desenvolvimento na UFPR e Mestre em Comunicação Social. E-mail: myrian@seti.gov.br

** Doutoranda em Meio Ambiente e Desenvolvimento na UFPR e Mestre em História pela UFPR.
} 


\section{Sociedade e ambiente}

\section{O natural e o social, componentes do ambiental}

A percepção dos problemas ambientais, generalizada a partir dos anos 1970, quando surgem, com mais frequiência, em âmbito internacional, manifestações ecológicas e questionamentos relacionados aos impactos das atividades humanas sobre a natureza e sua interface com os aspectos econômicos e sociais, tem gerado o uso e a disseminação de diversos termos para identificar problemas e soluções de ordem teórica e prática: ecodesenvolvimento, desenvolvimento sustentável, sustentabilidade, degradação ambiental, preservação do meio ambiente etc. Tais termos, usados comumente por cientistas e técnicos de diversas áreas do conhecimento, políticos, comunicadores e outros cidadãos voltados à discussão do tema, não chegam a constituir conceitos ou categorias claramente definidas e demarcadas; antes assinalam princípios e lógicas que norteiam a investigação e a compreensão de um objeto e de um problema que, embora antigo na história das ciências, tem apresentado, nas últimas décadas, aspectos novos que demandam respostas urgentes, a partir do entendimento das interações entre sociedade e natureza.

Adota-se nesse trabalho a compreensão da expressão questão ambiental como fruto da relação sociedadenatureza, que "diz respeito não apenas a problemas intrinsecamente naturais, mas também às problemáticas decorrentes da ação social", ${ }^{1}$ uma vez que não há na abordagem desta questão, segundo Rodrigues, separação entre os aspectos naturais e sociais.

A partir do fato de que a ação da sociedade sobre a natureza transforma, desnaturaliza, socializa esta nature$\mathrm{za}$, interessa-nos aqui delinear de forma mais precisa a utilização da expressão degradação socioambiental urbana, que já representa, do ponto de vista conceitual, um avanço em relação ao termo menos complexo degradação ambiental, largamente utilizado nas áreas biológicas e de engenharia ambiental, bem como na legislação sobre o tema.
Ao somar-se o termo "social" ao termo "degradação", levase em conta um elemento fundamental na constituição e transformação do ambiente natural ou cultural que, ao mesmo tempo, é causa e efeito da degradação. A utilização daquela expressão também implica no entendimento de meio ambiente urbano como "um habitat socialmente criado, configurado enquanto um meio físico modificado pela ação humana."2

Porém, antes de desenvolver uma análise sobre a degradação socioambiental propriamente dita, é preciso conjecturar sobre a origem do termo degradação. Originalmente, tal termo está ligado às descobertas da física que levaram à formulação do segundo princípio da termodinâmica, esboçado por Sadi Carnot, com relação às tecnologias das máquinas térmicas, e formulado com significado mais amplo por Clausius (1850). Tal princípio conclui que a energia mecânica irreversivelmente se transforma em calor, e que este só parcialmente pode ser transformado em trabalho. Assim, a energia que toma a forma de calor não pode reconverter-se inteiramente, ocorrendo portanto não a perda de energia (pois isto contradiz a primeira lei da termodinâmica baseada na conservação da energia), mas leva à degradação da energia. Esta diminuição irreversível da aptidão para transformar-se e para efetuar um trabalho, é denominada por Clausius de entropia. ${ }^{3}$ A entropia será explicada posteriormente por Boltzmann (1877) não apenas em termos da degradação da energia, mas da degradação da ordem, já que

O calor é energia própria aos movimentos desordenados das moléculas no seio deste sistema, e todo o aumento do calor corresponde a um aumento de agitação e a uma aceleração destes movimentos. É, portanto, pelo fato de a forma calorífica de energia comportar desordem nos seus movimentos que há uma inevitável degradação da aptidão para o trabalho. ${ }^{4}$

Os princípios da termodinâmica, ainda vinculados aos fundamentos da física newtoniana, foram problematizados

1 RODRIGUES, A. M. Produção e consumo do e no espaço: problemática ambiental urbana. São Paulo: Hucitec, 1998. p. 13.

2 JACOBI, P. Cidade e meio ambiente: percepções e práticas em São Paulo. São Paulo: Anna Blume, 1999. p. 14. Ver também esta questão em outros autores como Milton Santos, citado nas referências bibliográficas.

3 A discussão sobre estas leis e seus desdobramentos e influências no desenvolvimento das ciências encontra-se, dentre outros autores, em MORIN, E. $O$ método: a natureza da natureza. Lisboa: Publicações Europa-América, [19-] e em CAPRA, F. O ponto de mutação: a ciência, a sociedade e a cultura emergente. São Paulo: Cultrix, 1982.

4 MORIN, op. cit., p. 39. 
posteriormente, no decorrer do século 20, pelo desenvolvimento da mecânica estatística, da teoria da relatividade e da física quântica. Independente dos desdobramentos das investigações sobre o mundo físico, entretanto, o termo degradação no contexto da questão ambiental, foi reapropriado pela ciências ambientais, passando a ter um sentido genérico equivalente a alteração, transformação, destruição contínua, perda física.

A imprecisão da palavra degradação é justamente o motivo pelo qual ela é usada para se referir indistintamente aos desgastes dos solos agrícolas pelo uso de pesticidas e mecanização intensa do plantio, à poluição dos mares e dos rios pelo despejo de resíduos líquidos e sólidos, aos desmatamentos da Floresta Amazônica, à poluição do ar nas grandes cidades, às baixas condições de habitação, à falta de saneamento básico etc.

No âmbito da legislação ambiental brasileira, por exemplo, a Lei n. 6.938, de 31 de agosto de 1981, define degradação da qualidade ambiental como alteração adversa das características do meio ambiente. Atualmente, com poucas alterações, ${ }^{5}$ a expressão degradação ambiental qualifica os processos resultantes dos danos ao meio ambiente - qualquer lesão ao meio ambiente causada por ação de pessoa, seja ela física ou jurídica, de direito público ou privado, pelos quais se perdem ou se reduzem algumas de suas propriedades, tais como a qualidade ou a capacidade produtiva dos recursos ambientais.

A utilização do termo socioambiental significa, por sua vez, a constatação de que não se pode conceber ambiente e/ou natureza isoladamente, independente e indiferente à ação humana. Como tão bem assinalou Herbert de Souza, a vertente político-ideológica progressista - social-democrata ou socialista -, ao questionar o desenvolvimento do capitalismo e do socialismo, em seus efeitos sociais e políticos, detectou a exclusão econômica e política como causa do fracasso comum dos dois modelos históricos da modernidade, mas esta mesma vertente

Atuou como se existisse num mundo onde os homens e mulheres vivessem sem relação com a natureza, ou como se a relação com a natureza pudesse ser ignorada, sem produzir conseqüências fundamentais. Ao privilegiar as relações sociais, ignorou as relações naturais. Ao ver somente o rosto humano, os progressistas não foram capazes de ver a vida em todas as suas manifestações, e perderam a capacidade de ver todas as relações que unem os seres vivos e naturais. ${ }^{6}$

Já a vertente liberal, segundo o sociólogo, embora tenha muitas vezes ignorado o lado humano, viu o lado da natureza, "ajudou a completar o quadro e surpreendeu o capitalismo pelas costas, questionando seu impulso predador e sua tendência suicida escondida na voragem produtivista."”

Da contradição entre as duas vertentes político-ideológicas mais marcantes do final do século 20 surge a síntese que, "que colocou a questão ecológica na ordem do dia e se impôs ao pensamento moderno como um ponto de encontro da crítica do mundo atual e da busca de uma relação entre os homens e a natureza, portanto entre os homens e sua própria

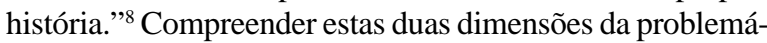
tica ambiental, frisadas por Herbert de Souza, implica estudar as alterações que ocorrem nos ecossistemas naturais, levando-se em conta o conhecimento da organização material e simbólica das sociedades e o modo como elas se apropriam e interagem com os ambientes naturais.

\section{Degradação socioambiental e cidadania}

Ao estudar os fenômenos ambientais no âmbito das cidades, surge a questão: o que é um ambiente urbano degradado? Como se pode caracterizar e avaliar a diferença entre uma alteração provocada por fatores estritamente naturais e aquela proveniente dos impactos da ação humana? Como identificar num ambiente construído - as cidades - as mutações do ambiente natural? Serão todas as atividades urbanas geradoras de degradação socioambiental? É possível estabelecer no ambiente urbano formas de apropriação do solo, do ar, das águas, que não provoquem ou que controlem a degradação? Como se configura a degradação socioambiental em espaços urbanos com especificidades geográficas e históricas diferenciadas? Qual

5 A lei federal citada foi alterada pela Lei 7.804, de 18 de julho de 1989, que mantém a mesma definição com relação ao termo.

6 SOUZA, H. de. Ecologia e democracia: duas vertentes questionam o desenvolvimento. Disponível em: <www.ibase.com.br/cidadania> Acesso em nov. 2000 . p. 1.

7 Ibid., p. 2

8 Id. 
é a importância da conformação histórica e sociocultural no processo de degradação urbana? Quais seriam os indicadores de sustentabilidade para o espaço urbano?

Do ponto de vista teórico, a reflexão sobre estas questões pode conduzir à percepção de que, atualmente, os princípios sobre os quais se baseiam as relações entre o mundo social e o natural produzem, freqüentemente, dicotomias inconsistentes e falsas contradições. ${ }^{9}$ Respostas diferenciadas às questões acima colocadas, ou mesmo a falta de respostas, revelam também que ainda não se encontra devidamente assimilada a concepção de que o pensamento ecológico produzido nas últimas décadas esteja promovendo uma "revolução" nos atuais paradigmas epistemológicos que balizam o entendimento das relações homem-natureza, interferindo decisivamente na construção científica das mais diversas áreas do conhecimento; entretanto, especificamente do ponto de vista das práticas urbanas, este novo pensamento vem transformando radicalmente a abordagem do ambientalismo no processo de urbanização e, particularmente, no que diz respeito à gestão socioambiental urbana como um problema público, inserido em uma nova visão de gestão das cidades, e moldado por interesses divergentes.

Este novo pensamento permeado pelas questões ambientais vem permitindo um novo olhar crítico com relação à observação empírica da realidade da maioria das metrópoles mundiais e, com maior ênfase, nas grandes metrópoles dos países menos desenvolvidos, que, por apresentarem graves problemas de infra-estrutura e de ordem política, social e econômica, tornaram-se "modelos" de degradação ambiental.

Verificam-se nesses grandes assentamentos humanos, problemas ambientais semelhantes, que causam o mesmo tipo de efeitos degradantes sobre o ambiente urbano, e sobre uma área geográfica muito maior que aquela sobre a qual se estende a metrópole, atingindo mesmo toda uma região e avançando para a área rural, que, em si, já apresenta problemas ambientais específicos, que por sua vez também pode trazer conseqüências degradantes para o ambiente urbano. ${ }^{10}$
Espaços urbanos com especificidades físico-naturais e socioculturais diferenciadas apresentam também processos de degradação socioambiental semelhantes. Alva ${ }^{11}$ aponta gravíssimos problemas ambientais da cidade do México que podem ser comparados aos problemas ambientais das cidades de São Paulo ou de Caracas. São cursos d'água degradados, transformados em esgotos a céu aberto, que também recebem efluentes industriais e lixo doméstico; áreas rurais próximas aos centros urbanos, invadidas por visitantes de fim-de-semana; extinção de matas originais e de paisagens naturais, com bosques e mananciais; terras erodidas; inundações originadas pelo desnudamento da camada vegetal, com a conseqüente lavagem do solo e transporte de materiais até o fundo dos vales (retenção das águas pluviais e assoreamento de rios e lagos); concentração de líquidos tóxicos nos aterros sanitários que, transportados pela água da chuva, atingem o subsolo, contaminando mananciais e lençóis freáticos; extração de terra e pedras para construção; formação de cúpulas térmicas causadas pelo aquecimento da superfície das cidades; descargas das redes coletoras de esgotos, sem tratamento prévio, em rios, lagos e mares, com a ameaça de extinção da vida aquática; emissão de gases dos automóveis e engarrafamentos de trânsito que causam graves problemas de poluição do ar, com conseqüências danosas para a saúde da população - doenças respiratórias e stress, por exemplo - e prejuízos econômicos; dentre outros.

Tais aspectos degradados da natureza no âmbito urbano são agravados e, ao mesmo tempo, agravam, os problemas sociais, principalmente aqueles relacionados com a pobreza. Assinale-se que a relação entre pobreza e degradação ambiental é um tema recorrente e uma preocupação manifesta em todas as discussões sobre o urbano, sendo muito frisado nos diversos documentos e relatórios, nacionais e internacionais, que vêm sendo produzidos nas últimas décadas.

Herculano ressalta que para o Relatório Brundtland ${ }^{12}$ as causas de deterioração ambiental são identificadas em três campos: no uso de tecnologias poluidoras; no aumen-

9 SOUZA, op. cit., p. 2.

10 Um exemplo ilustrativo: na Região Metropolitana de Curitiba utiliza-se, na lavoura de batata, "coquetéis" de venenos em níveis assustadores - ninguém toma providências, pois politicamente não é interessante indispor-se contra os "batateiros". Notícia veiculada pelo jornal Gazeta do Povo, em setembro de 1998, afirmava que um Posto de Saúde 24 Horas, em Curitiba, precisou ser fechado para descontaminação, depois de atender a um agricultor, plantador de batata, contaminado por três diferentes produtos químicos utilizados em sua lavoura; os médicos e atendentes do posto também foram internados.

11 ALVA, E. N. Metrópoles (In)Sustentáveis. Rio de Janeiro: Relume Dumará, 1997. p. 40-42.

12 Relatório Brundtland é como ficou conhecido mundialmente o relatório da Comissão Mundial sobre Meio Ambiente e Desenvolvimento (1991), organizado pela presidente da Comissão, Gro Brundtland, publicado no Brasil em 1988 pela Editora da FGV. Em 1991, o relatório foi reeditado com o título de Nosso futuro comum. 
to demográfico; na intensificação e expansão da miséria. As soluções de desenvolvimento sustentável propostas por este Relatório são: reorientação tecnológica e institucionalização de meios de fiscalização internacionais; controle populacional para o Terceiro Mundo; políticas de ajustes e de ajuda financeira dos países ricos aos pobres. Herculano critica, entretanto, a postura do Relatório, por este afirmar que "a pobreza e a deterioração ambiental formam um círculo vicioso, no qual cada termo é causa e efeito do outro." ${ }^{13}$ Classifica como injustiça cega, o fato do Relatório "não mencionar com a mesma insistência a degradação ambiental trazida pelo crescimento exponencial e o consumismo do Primeiro Mundo", ${ }^{14}$ colocando a pobreza e deterioração ambiental como efeitos indesejáveis de um modelo de crescimento que busca o incremento de capital e não o atendimento às necessidades humanas.

O Relatório do Brasil para a Conferência das Nações Unidas sobre Meio Ambiente e Desenvolvimento, realizada no Rio de Janeiro, em 1992, citando o Programa das Nações Unidas para o Meio Ambiente - PNUMA -, não avança muito em relação ao Relatório Brundtland, identificando basicamente duas causas para a crise ambiental: a pobreza e o mau uso da riqueza.

O documento do Banco Mundial conhecido como Agenda Marrom ${ }^{15}$ aponta os cinco maiores problemas da poluição no Brasil: saneamento básico inadequado, poluição do ar nas áreas metropolitanas, poluição das águas nas áreas urbanas, gestão precária de resíduos sólidos e poluição localizada grave. É importante, entretanto, ressalvar que esta agência internacional restringe o entendimento do problema ambiental urbano àqueles com custos predominantemente domésticos, excluindo, portanto, aspectos de interesse ambiental global. Assim, os problemas se alinhariam em dois blocos: domésticos e globais (e não mais em rurais e urbanos). Em relação aos problemas e setores inse- ridos na esfera global estaria a conservação e o gerenciamento de recursos naturais, questões relativas à biodiversidade e mudanças climáticas. No âmbito doméstico e urbano, âmbito a que se restringe esta agenda, o enfoque se daria sobre o aperfeiçoamento técnico-administrativo institucional, controle da poluição industrial, saneamento básico, poluição hídrica e melhorias ambientais urbanas.

No âmbito local, é possível constatar, por exemplo, que na Grande Curitiba, metrópole de 2 milhões e meio de habitantes, os problemas e efeitos da degradação socioambiental são semelhantes àqueles de outras grandes cidades, ainda que as percepções da população local sobre eles revelem a idéia de que ocorram em menor escala. Uma pesquisa exploratória ${ }^{16}$ sobre $O$ que é problema ambiental urbano na mídia impressa local? indicou os problemas ambientais urbanos de Curitiba apontados nas notícias de jornais - de acordo com os principais problemas ambientais verificados nas grandes cidades brasileiras ${ }^{17}$ - revelando dentre os mais freqüentes no período abordado: o acúmulo, manuseio e destinação final do lixo urbano; a degradação do patrimônio histórico-cultural e a conservação dos equipamentos e espaços públicos; os problemas de trânsito e educação no trânsito; a poluição sonora, visual, do ar e dos recursos hídricos; a falta e os problemas de transporte coletivo; o desequilíbrio da fauna, flora e clima urbanos; a ocupação irregular de áreas ambientalmente frágeis; a escassez e a contaminação da água; a diminuição da cobertura vegetal; a falta de espaços públicos de lazer; a falta de infra-estrutura e saneamento básico; os problemas de uso e ocupação irregular ou inadequada do solo.

Um olhar generalizado, e atento, sobre a qualidade ambiental das principais cidades brasileiras evidencia que, além das consequiências da pobreza se confundirem com as conseqüências da degradação ambiental urbana, são agravadas pela fragilidade de condições para o exercício da ci-

13 HERCULANO, S. C. Do desenvolvimento (in)suportável à sociedade feliz. In: GOLDENBERG, M. (Org.). Ecologia, ciência e política: participação social, interesses em jogo e luta de idéias no movimento ecológico. Rio de Janeiro: Revan, 1992. p. 28.

14 HERCULANO, op. cit., p. 27.

15 BANCO MUNDIAL, Brasil: Gestão dos problemas da poluição/A Agenda Ambiental Marrom. Relatório de Política. Washington: Banco Mundial, 1998. v. 1. 16 LIMA, M. R. D. V. Relatório da pesquisa exploratória sobre problemas ambientais urbanos apontados pela mídia impressa de Curitiba-PR. Curitiba, mimeog. 1999. A pesquisa revela os problemas mais freqüentes apontados pelas matérias do jornal, no período abordado: o acúmulo, manuseio e destinação final do lixo urbano ; a degradação do patrimônio histórico/cultural e a conservação dos equipamentos e espaços públicos; os problemas de trânsito e educação no trânsito; a poluição sonora, visual, do ar e dos recursos hídricos; a falta e os problemas de transporte coletivo; o desequilíbrio da fauna, flora e clima urbanos; a ocupação irregular de áreas ambientalmente frágeis; o desabastecimento e a contaminação da água; a diminuição da cobertura vegetal; a falta de espaços públicos de lazer; a falta de infra-estrutura e saneamento básico; os problemas de uso e ocupação irregular ou inadequada do solo.

17 A partir de pesquisa feita no site da Internet: Infra-estrutura e meio ambiente. Disponível em: <www.gcsnet.com.br/oamis/civitas/ci150220.html> 
dadania. É imprescindível assinalar, embora o objetivo não seja aqui o de aprofundar estas questões, que parte dos problemas destacados têm sua origem na falta de acesso da população à educação básica e ambiental e à permanente contradição verificada entre a legislação de uso e ocupação do solo urbano e os interesses vinculados à especulação imobiliária, dentre outras, as quais refletem as desigualdades econômicas e sociais da sociedade brasileira.

Outras pesquisas, como por exemplo $O$ que o brasileiro pensa da ecologia ${ }^{18}$ além de inúmeras reportagens veiculadas pelos meios de comunicação de massa, demonstram que a visibilidade da degradação socioambiental urbana é percebida pelos indivíduos, que se apresentam mais ou menos conscientes das transformações ambientais que afetam suas condições de moradia, de trabalho e de saúde; entretanto, os conflitos sociais resultantes da apropriação social da natureza motivada por interesses privados, na maioria das vezes conflitantes com os direitos ambientais dos indivíduos e coletividades, não são associados ao frágil exercício da cidadania, esfera em que os direitos mais elementares, como

Os direitos à educação, à saúde, à velhice são, por seu turno, apenas formais, permanentemente submersos pela crise fiscal do Estado e pela avidez das elites. ${ }^{19}$ Ao contrário, a este quadro precário da cidadania no Brasil somam-se as limitações que as condições ambientais de existência colocam para o exercício pleno dos direitos adquiridos por grande parte das populações. ${ }^{20}$

Carvalho esclarece que:

Os conflitos ambientais são a expressão de conflitos sociais que têm a natureza como suporte. Revelam muitas vezes o confronto entre os interesses privados e o bem coletivo. Embora os elementos que constituem o meio ambiente não sejam passíveis, em sua maioria, de apropriação privada, como o ar, a água, os rios etc, podem estar sujeitos a um uso que favorece interesses privados, em detrimento de uma coletividade. ${ }^{21}$
Após considerar a degradação socioambiental urbana como uma forma específica de degradação ambiental, ainda pouco explorada em termos de sua dimensão teórica e prática - produção de conhecimentos específicos e interdisciplinares bem como ações efetivas para melhorar a qualidade de vida urbana - e apontar alguns dos problemas socioambientais urbanos, locais e globais, agravados pela fragilidade do exercício da cidadania, especialmente nos países em desenvolvimento, como o Brasil, cabe apreender ainda a atuação das políticas públicas frente à questão ambiental, que por por tratar do bem comum, envolve a participação dos governos, das instâncias políticas e dos vários setores da sociedade organizada.

\section{Políticas públicas e ambiente}

\section{A internacionalização da questão ambiental}

A preocupação com os problemas ambientais até meados do "breve" século 20, como diz Hobsbawm, restringia-se a pequenos círculos de entusiastas da vida silvestre e outros protetores de raridades humanas e naturais. ${ }^{22}$ Pode-se atrelar este fato, por um lado, ao efeito do crescimento econômico entre os anos 1950 e 1970, que expandia a crença na ideologia do progresso dominante, sendo a natureza representada como uma fonte de recursos inesgotáveis a satisfazer as "necessidades" humanas. Por outro lado, as estratégias de modernização e desenvolvimento desse período, organizadas em dois modelos, um centrado no papel do mercado e o outro no do Estado, começavam a propiciar em âmbito mundial inquietações de ordem cultural, social e política, que iriam deflagrar movimentos sociais voltados para lutas específicas, como os movimentos pela paz, a favor da emancipação feminina, contra o racismo, pela conservação da natureza.

A questão ambiental que, até os anos 70, era uma preocupação de preservacionistas e conservacionistas, imbuída de valores estéticos, científicos e sociais extrapolíticos (embora permeada em vários aspectos por ideologias polí-

18 CRESPO, S.; LEITÃO, P. O que o brasileiro pensa da ecologia. Rio de Janeiro: ISER, 1993.

19 ACSELRAD, H. Cidadania e meio ambiente. Disponível em: <www.ibase.com.br/cidadania> Acesso em: nov. de 2000. p. 1.

20 Ibid., p. 3.

21 CARVALHO, I. C. M. Educação, meio ambiente e ação política. Texto apresentado no curso de capacitação em educação ambiental para professores da rede municipal do Rio de Janeiro, em 19 de março de 1992.

22 HOBSBAWM, E. Era dos extremos. [S. 1.: s. n.], 1998. p. 257. 
ticas) passa a ser discutida também no âmbito do Estado. A Conferência de Estocolmo, em 1972, reunindo países ricos e pobres, tornou-se nesse sentido um marco histórico por diversas razões: propiciou a legitimação política mundial da questão ambiental, favoreceu o posterior surgimento de um espaço público mundial, facilitando e fortalecendo o debate ambientalista em diferentes países e, sob a reação dos países do hemisfério sul, ampliou o conceito de meio ambiente - que compreendia os problemas ecológicos num sentido estrito - englobando a partir daí também os problemas da fome e da pobreza. ${ }^{23}$

Como salienta Leis, somente hoje, em retrospectiva, pode-se avaliar a importância de Estocolmo-72 para o grande salto do ambientalismo constituído gradualmente como um movimento multissetorial que "foi incorporando setores, problemas e perspectivas vindo das ciências naturais, da sociedade civil, do Estado, da economia e das religiões." 24 Também Castells enfatiza que, desde a década de 1960, “o ambientalismo não tem-se dedicado exclusivamente à observação dos pássaros, proteção das florestas e despoluição do ar (...) Uma série de outras causas foram incorporadas à proteção da natureza, situando o movimento em um cenário bastante amplo de direitos e reivindicações." ${ }^{25}$ Nos anos 90 , várias questões sociais começaram a fazer parte do movimento ambientalista cada vez mais heterogêneo. Esta evolução e incorporação de múltiplas áreas, da natureza aos conglomerados urbanos, da ciência à religião, das questões sociais às econômicas, fazem com que Castells afirme que, embora as ações coletivas, políticas e discursos agrupados sob a rubrica do ambientalismo sejam tão diversificados, "é justamente essa dissonância entre teoria e prática que caracteriza o ambientalismo como movimento social descentralizado, multiforme, orientado à formação de redes e de alto grau de penetração." ${ }^{26}$

No âmbito do Estado, cresceu o número de países que incluíram programas ambientais em suas agendas: antes da Conferência de Estocolmo, em 1971, somente 12 países tinham agências estatais voltadas para o meio ambiente, a maioria constituída por países desenvolvidos. Já em 1981, mais de 140 países haviam criado órgãos administrativos nessa área, sendo quase proporcional a relação en- tre os países mais desenvolvidos e os menos desenvolvidos $;^{29}$ não obstante pudesse (e ainda possa) ser questionada a efetiva atuação e eficiência dos organismos públicos ambientais criados, à medida que a sua proliferação se deu em diversos países, mais pela demanda e pressão internacional de um modelo capitalista que ansiava por um novo discurso ético e, sobretudo, por novos mercados e oportunidades econômicas, do que propriamente como resultado de uma conquista da organização social e política de cada país.

Paralelamente ao esverdeamento das políticas públicas também proliferaram nesses últimos trinta anos a formação de organizações não-governamentais - ONGs, representantes das mais diversas matizes político-ideológicas, que a princípio se configuram instituições organizadas por cidadãos não vinculados ao Estado ou ao mercado, mas que pretendem dialogar com estes e redefinir o papel dos indivíduos e da sociedade na esfera pública. Hoje, em muitos casos, tal como a criação de instituições governamentais na área ambiental, o alcance da mobilização e formação de muitas ONGs pode ser questionado em termos de uma recuperação da importância e existência de uma esfera pública, entendida nos termos explicitados por Arendt, como o espaço moralmente legítimo da liberdade e da ação política. ${ }^{28}$ Pode-se argumentar também que parte do sucesso do movimento ambientalista se deve ao fato de que:

Mais do que qualquer outra força social, ele tem demonstrado notável capacidade de adaptação às condições de comunicação e mobilização apresentadas pelo novo paradigma tecnológico. Embora boa parte do movimento dependa das organizações de base, suas ações ocorrem em razão de eventos que chamam a atenção da mídia. ${ }^{29}$

O que lhes dá uma legitimação bem maior que a atribuída a outras causas, mas também espetaculariza o tema ambiental e o transforma em produto para consumo imediato, como qualquer outro absorvido pela rede mediática.

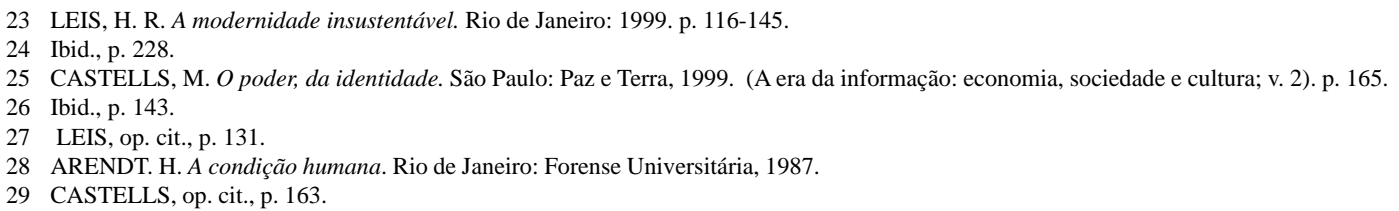


Todavia, ao longo dessas últimas três décadas, o ambientalismo têm-se apresentado como uma resposta alternativa e democratizante, ao menos para as sociedades capitalistas contemporâneas, permeadas pela exacerbação do individualismo e pela redução da esfera pública a um espaço onde se debate publicamente os interesses privados. ${ }^{30}$

\section{Políticas ambientais no Brasil}

O Brasil, como muitos países menos desenvolvidos, na década de 70, estava orientado por uma política estatal desenvolvimentista e reguladora das atividades socioeconômicas. Este modelo, segundo Monosowsky, agravou os problemas urbanos das principais cidades do país, com o crescimento da poluição industrial, a falta de saneamento básico e os problemas de abastecimento de água. Certos setores da população sensibilizaram-se e organizaram-se, enquanto movimento social, sobre as questões ambientais. Neste sentido, resultados de pesquisas de opinião pública realizadas em São Paulo, em 1975, já apontavam que "a maioria da população considera a poluição ambiental como seu maior problema, prioritário até mesmo em relação às questões econômicas." ${ }^{\prime 1}$ Ou seja, a pesquisa demonstrava a preocupação da população com os problemas ambientais, que pioravam sua qualidade de vida, contrapondo-se aos autores que entendiam que as preocupações das populações dos países menos desenvolvidos não passariam pelo meio ambiente, afirmando ser esta uma questão dos países mais desenvolvidos.

Coerente com esta concepção, o governo brasileiro chega a sustentar, na Conferência de Estocolmo, em 1972, que

A proteção ao meio ambiente seria um objetivo secundário e não prioritário para os países em vias de desenvolvimento, e em conflito com o objetivo central e imediato do crescimento econômico. (...). A proteção do meio ambiente seria, portanto, mais um obstáculo ao desenvolvimento. ${ }^{32}$

A palavra de ordem era então poluição como sinônimo de progresso.

Ainda nos anos 1970, em meio a crise do Estado brasileiro, decorrente dentre outros fatores do sistema político vigente, do surgimento de movimentos ambientalistas, do agravamento dos problemas urbanos e da crítica social ao "milagre brasileiro" e, em certa medida, revendo sua posição em Estocolmo-72, é criada no Brasil, em 1974, a Secretaria Especial de Meio Ambiente. Sucede-se, a partir daí, uma ampla edição de leis ambientais em âmbito nacional. ${ }^{33}$ Os estrategistas governamentais percebem, neste período, que o uso das questões ambientais como marketing, e como forma de desviar a atenção da opinião pública dos problemas econômicos e políticos, é muito mais eficiente que a sua negação. Estratégia que, de certa forma persiste até hoje, e, segundo Monosowsky, permite ao governo mostrar eficiência e elaborar "discurso consensual" em relação a um aspecto social específico. Neste cenário contraditório, onde as ações governamentais na área ambiental funcionam apenas como "cortina de fumaça" para que o livre jogo das forças de mercado manifeste-se em toda sua amplitude, esta estratégia diversionista pode, entretanto, ser considerada como perspectiva para a geração de políticas de desenvolvimento sustentável a longo prazo.

Porém, a associação da percepção dos problemas urbanos, como uma crescente degradação da qualidade de vida nas grandes cidades, à questão ambiental ainda é recente. Ou melhor, inicialmente a percepção dos problemas urbanos é vinculada a uma corrente preservacionista que os aponta como necessidade de criar e/ou ampliar áreas verdes no espaço urbano ou denunciar cortes de árvores. Somente no final dos anos 1980

Com a agudização de problemas de enchentes ou de abastecimento de água (contaminação de mananciais,

\footnotetext{
30 Ver sobre conceitos de esfera pública e esfera privada ARENDT, H. A condição humana. Rio de Janeiro: Forense Universitária, 1987; e HABERMAS, J. Mudança estrutural da esfera pública. Rio de Janeiro: Tempo Brasileiro, 1984.

31 MONOSOWSKY, E. Políticas ambientais em desenvolvimento no Brasil. Caderno Fundap, p. 18.

32 Id.

33 As medidas governamentais brasileiras relacionadas ao meio ambiente até a década de 1970, caracterizavam-se essencialmente pela regulamentação da exploração dos recursos naturais diante de um crescente desenvolvimento industrial e não motivada por uma percepção científica ou ética de que o meio ambiente precisava ser protegido, tampouco relacionava desenvolvimento urbano com ecologia. A legislação nacional, vinculada de alguma forma à conservação da natureza (para racionalizar a exploração de recursos), limitava-se à criação do Código Florestal (1934; 1965), do Código de Caça e de Pesca (1967) e do Código de Mineração (1968). Somente em 1980 foi criado, por exemplo, o Código das Águas.
} 
racionamentos etc.), a imprensa começa a enfatizar questões relativas aos serviços urbanos, trazendo muitas vezes subjacente a idéia de incapacidade ou morosidade do setor público em responder às demandas por infraestrutura e serviços. ${ }^{34}$

Certamente, a criação de organismos e estruturas administrativas estaduais e municipais voltadas ao meio ambiente, além de corresponderem ao cumprimento das leis estabelecidas pela Constituição Federal de 1988, buscam acompanhar as transformações sociais, adaptar-se às reformas administrativas, atualizar as atividades técnico-burocráticas, tendo como referência as propostas da agenda político-ambiental internacional, expressas na Conferência Rio-92, na Conferência das Nações Unidas sobre Assentamentos Humanos (Habitat II), em 1996, e sobretudo, obter financiamentos para o desenvolvimento urbano junto às instituições internacionais.

Conquanto sejam legais e/ou legítimos os esforços de promover a sustentabilidade urbana, os conflitos e também a conjugação de interesses entre os diversos agentes produtores da cidade - agentes governamentais, empresariais, consumidores/habitantes da cidade -, colocam em evidência a complexidade dos problemas urbanos e a necessidade de se proceder a uma reflexão sobre as experiências concretas que levam ao processo de degradação socioambiental urbana; neste contexto, é preciso também analisar como se colocam historicamente os diversos atores frente à idéia de sustentabilidade e de degradação do ambiente da cidade e quem são os principais responsáveis pelas condições atuais da vida urbana.

\section{Discursos da (in) sustentabilidade urbana}

Nas duas últimas décadas do século 20, a disseminação mundial da noção de desenvolvimento sustentável banalizou, em certa medida, a crítica à modernidade feita pelo ambientalismo, sendo esta nação apropriada por diversos atores sociais interessados em estabelecer concorrentes estratégias de legitimação e autoridade. Na concepção de Acselrad, estabelecem-se matrizes discursivas de sustentabilidade, tais como as que propugnam limite quantitativo ao crescimento econômico e a pressão que ele exerce sobre os recursos naturais (matriz da escala); combinação entre racionalidade econômica e espaço não-mercantil planetário (matriz da eficiência) até aquelas que procuram articular princípios de justiça e ecologia (matriz da eqüidade) e debater os valores morais que norteiam as interações de base material do desenvolvimento com as condições de continuidade da vida no planeta (matriz da ética). ${ }^{35}$

Com relação às cidades, o uso da noção de sustentabilidade urbana torna-se ainda mais complexo, pois os espaços urbanos são incapazes de satisfazer todas as necessidades humanas, sendo dependentes de outras espacialidades, próximas ou distantes; são grandes consumidores de energia; produzem enorme quantidade de resíduos, que não podem ser inteiramente eliminados ou reaproveitados; provocam profundas mudanças na ocupação da terra e no uso do solo, decorrentes da transformação de áreas naturais ou rurais em áreas urbanas, gerando diversos impactos ambientais e socioeconômicos ${ }^{36}$ (documento Odum).

Assim, as diferentes noções de desenvolvimento sustentável em cidades, disseminadas desde que as questões ambientais urbanas tornaram-se uma preocupação generalizada e insistentemente divulgada pela mídia, vêm sendo usadas mais no sentido de caracterizar algumas iniciativas dos poderes públicos/empresariais no âmbito urbano. As estratégias baseadas na noção de sustentabilidade, além de serem meios para se alcançar uma pretensa combinação sustentável de desenvolvimento e conservação ambiental, ambicionam também uma forma participativa de planejamento e execução de políticas públicas. Conseqüentemente, a análise das ações e dos discursos dos agentes produtores do espaço urbano - Estado, ONGs, empresas privadas, associações de moradores etc. -, suas estratégias, instrumentos e políticas para a construção da sustentabilidade ambiental nas cidades são fundamentais para se identificar

34 PACHECO, R. S. et al. Atores e conflitos em questões ambientais urbanas. Centro de Estudos de Administração Pública. Governo. São Paulo: Fundação Getúlio Vargas, [19-].

35 ACSELRAD, H. Discursos de sustentabilidade urbana. Estudos Urbanos e Regionais, n. 1, p.79-88, maio 1999.

36 Observe-se que alguns autores estudiosos da Ecologia afirmam que "as cidades apresentam muitas características dos ecossistemas naturais, por exemplo: produção, consumo, concentração de energia, decomposição e ciclo de materiais." Cf. ODUM. Curso de ecossistemas e políticas públicas. Parte II: Tipos de ecossitemas. Cap. 20: Sistemas urbanos. leia@fea.unicamp.br 
o comprometimento de cada agente no processo de degradação urbana e/ou na busca de equacionar os problemas decorrentes da interação entre ambiente natural e ambiente construído.

Com relação à sustentabilidade urbana, Lipietz, em uma visão pessimista, compartilhada com outros analistas dos problemas ambientais urbanos, afirma que, a partir dos anos 1990, o ambiente urbano existente - isto é, resultante da gestão da crise socioeconômica dos anos 1970-80 - se impõe como problema insuperável, e não mais como espaço para uma solução, para as megalópoles mais engajadas nos modelos "flexíveis". Congestionamentos, poluições, guetos urbanos não favorecem, de forma alguma, a mobilização em torno de um projeto coletivo sustentável. Mas, o autor ressalva que

Qualquer que seja o "estado dos lugares", por mais degradado que seja, a reconstituição de um espaço organizado como forma espacial de compromissos sociais negociados resta como único objetivo para as forças progressistas no domínio urbano. ${ }^{37}$

Indicando aí um possível caminho para a gestão socioambiental urbana.

Entretanto, negociar compromissos sociais parece ser bastante difícil se concordarmos com Monosowsky, ao analisar o panorama brasileiro que

A organização dos grupos sociais e comunidades afetados por projetos de desenvolvimento mostra-se ainda precária e incipiente na maioria dos casos. $\mathrm{O}$ acesso aos meios de expressão e comunicação desses atores sociais é ainda bastante limitado, assim como o acesso à informação. Estas são restrições significativas à sua participação nos processos de negociação social dos projetos. $^{38}$

Este entendimento pode, em parte, explicar por que a evolução significativa presente na concepção das políticas ambientais brasileiras não é acompanhada, na prática, por resultados positivos quanto à manutenção e melhoria das condições de vida e preservação dos recursos naturais.

\section{Considerações Finais}

A questão ambiental, tal como apresentada aqui, na sua evolução teórica e prática, incorpora a questão urbana, embora por diversas vezes, e ao longo da trajetória histórica das cidades e das suas representações sociais, a natureza tenha sido considerada algo a parte, estranha e antagônica, algo a ser escondido ou modificado, algo a ser destruído ou desnaturalizado. Hoje, diante da dimensão e complexidade que assumiram os problemas socioambientais, a questão urbana é percebida, cada vez mais, na sua estreita relação com a natureza e não na sua dissociação. Isto implica, sem dúvida, uma revisão profunda no modo de pensar, planejar e executar políticas públicas; no modo de produzir e reproduzir o espaço urbano, no modo de viver e conviver nas cidades.

A reflexão sobre as dinâmicas natural e social e os processos de degradação socioambiental torna possível compreender que o entendimento da gestão ambiental nas cidades, sobretudo nas metrópoles, necessita ser ampliado e reconstruído, incluindo uma reavaliação do próprio conceito de gestão urbana, da atuação do poder local (municipal) na busca de soluções urbanas adequadas, das políticas públicas vigentes, das intervenções tecno-científicas, do uso dos instrumentos comunicacionais, do papel das instituições sociais, das experiências comunitárias com relação aos usos sociais e econômicos dos recursos naturais.

E não há um único caminho a seguir, ou um modelo de gestão urbana a adotar. O que a questão socioambiental sinaliza, a dinâmica urbana aponta, e os estudos sobre o ambiente urbano podem verificar, é que os caminhos são múltiplos, as formas de gestão variadas, porque há de se considerar frente aos problemas urbanos e à degradação socioambiental, a complexidade das realidades física, biológica e antropossociais que constituem e produzem os espaços urbanos. 


\section{REFERENNCIAS}

ACSELRAD, H. Cidadania e meio ambiente. Disponível em: 〈http:// www.ibase.com.br/cidadania>, Acesso em: nov. 2000.

. Discursos da sustentabilidade urbana. Revista Brasileira de Estudos Urbanos e Regionais, Campinas, n. 1, maio 1999.

ALVA, E. N. Metrópoles (In)sustentáveis. Rio de Janeiro: Relume Dumará, 1997.

ARENDT, H. A condição humana. Rio de Janeiro: Forense-Universitária, 1987.

ARQUIVO PÚBLICO (PR). História administrativa do Paraná: criação, competências e alterações das unidades administrativas da Província e do Estado. Curitiba: Imprensa Oficial/DEAP, 2000.

CAPRA, F. O ponto de mutação: a ciência, a sociedade e a cultura emergente. São Paulo: Cultrix, 1982

CARVALHO, I. C. M. Educação, meio ambiente e ação política. Disponível em: 〈www.ibase.com.br/cidadania〉, Acesso em: nov. 2000.

CASTELLS, M. O poder da identidade. São Paulo: Paz e Terra, 1999.

CRESPO, S.; LEITÃO, P. O que o brasileiro pensa da ecologia. Rio de Janeiro: ISER, 1993.

GAZETA DO POVO. Curitiba. 1999. ano 81. Disponível em: <http://www.gazetadopovo.com.br> Acesso diário: 25 maio à 25 jun. 1999.

HABERMAS, J. Mudança estrutural da esfera pública. Rio de Janeiro: Tempo Brasileiro, 1984.

HERCULANO, S. Do desenvolvimento (in) suportável à sociedade feliz. In: GOLDENBERG, M. Ecologia, ciência e política: participação social, interesses em jogo e luta de idéias no movimento ecológico. Rio de Janeiro: Revan, 1992.

HOBSBAWM, E. Era dos extremos: o breve século XX (1914-1991). São Paulo: Companhia das Letras, 1998.
INFRA-ESTRUTURA e meio ambiente. Disponível em: <http://www.gcsnet.com.br/oamis/civitas/ci150220.html> Acesso em: jun. 1999.

JACOBI, P. Cidade e meio ambiente: percepções e práticas em São Paulo. São Paulo: Anna Blumme, 1999.

LEIS, H. R. A modernidade insustentável: as críticas do ambientalismo à sociedade contemporânea. Rio de Janeiro: Vozes, 1999.

LIMA, M. R. D. V. Relatório de pesquisa exploratória sobre problemas ambientais urbanos apontados pela mídia impressa de Curitiba-PR. Curitiba: mimeog., 1999.

LIPIETZ, A. Uma visão regulacionista sobre o futuro da ecologia urbana. Cadernos IPURR/UFRJ, ano 8, n. 1, abr. 1994.

MONOSOWSKI, E. Políticas ambientais e desenvolvimento no Brasil. Cadernos Fundap, n. 16, jun. 1989.

MORIN, E. O método: a natureza da natureza. Lisboa: $\mathrm{Pu}-$ blicações Europa-América, [19-].

CONFERÊNCIA DAS NAÇÕES UNIDAS SOBRE MEIO AMBIENTE E DESENVOLVIMENTO, 1992, Rio de Janeiro. Agenda 21. Curitiba: Ipardes, 1997.

PACHECO, R. S. et al. Atores e conflitos em questões ambientais urbanas. Espaço \& Debates: Revista de Estudos Regionais e Urbanos, São Paulo, n. 35, 1992.

PARANÁ. Diário Oficial do Estado. Curitiba: Imprensa Oficial, 1974; 1987; 1992.

RODRIGUES, A. M. Produção e consumo do e no espaço: problemática ambiental urbana. São Paulo: Hucitec, 1998.

SOUZA, H. de. Ecologia e democracia: duas vertentes questionam o desenvolvimento. Disponível em: <http:// www.ibase.com.br/cidadania> Acesso em: nov. 2000.

WORLD BANK. Brazil: managing pollution problems/The brown environmental agenda. Washington: World Bank, 1998. v. 2, Annexes. 